\title{
PharmD: The need for Indians
}

\author{
Swapnil Ashok Mundhe \\ Student, Shivlingeshwar College of Pharmacy-PharmD, Almala, Latur, Maharashtra, India \\ *Corresponding Author: Swapnil Ashok Mundhe \\ Email: smundhe0@gmail.com
}

\begin{abstract}
With gradually increasing hospital faculty in India new challenges are betide in healthcare profession. escalation the concept of clinical pharmacist which turns to lead the PharmD program in India. The pharmacy profession is over the hill in India with unrecognized profession behind the counter of Pharmacy store and traditional workload of pharmacist. But the perspective of PharmD is totally different it aims that to make drastic changes in healthcare sector. Well designed syllabus with detail knowledge of pharmacology and therapeutical aspects as a Pharmacist which make a good clinical practitioner's as a clinical pharmacist. And now this is time to build up more healthier country by providing drug information more accurately by participating in real clinical practice.
\end{abstract}

Keywords: Healthcare profession, Patient counseling, Clinical pharmacist.

\section{Introduction}

PharmD is Latin term which stand for 'pharmaciae doctor' which means 'Doctor of pharmacy'.

As per study India facing shortage of more than 600,000 physicians and the researchers found that there is lack of healthcare workers who are properly trained in administering and handling of antibiotics which is preventing patients from accessing life-saving drugs.NPSA statistics show that $59.3 \%$ of medication errors occur during the administration stage. Therefore identifying and resolving the medication, administration errors will improve the patient care.

If we look forward Indian healthcare system need supplemental effective, efficient and more life saving with minimal medication errors and with appropriate drug management and handling of drugs in right hands and yes we Pharmdians are ready to serve the community.

PharmD doctor can make evolutionary change by overcome prescription audit report, medication order errors. PharmD is milestone event in the evolutionary process of pharmacy practice.Total 6 year $(5+1$ programme-5years of academic studies+1year of residency) duration intended to make drastic changes in health sector. In full academics pharmD students learn medicinal chemistry, pharmacology, pharmacokinetics, pharmacodynamics, pharmacogenetics, pharmacotherapy \& pharmacoeconomics, human physiology and pathophysiology.

However most of the nation's abroad like USA, Canada, and Australia.....etc. PharmD has turned the most trusted profession because of it aims at molding up students with better knowledge and skills to provide professional care to patient. With patient counseling and work as clinical pharmacist.

\section{Objectives}

1. To communicate with patients and the community.

2. To demonstrate skills of the National Health Programs and schemes.

3. To manage health care system, in co-operation with patients, doctors and other health care sector.
4. To conduct patient interview with the objective of developing patient data and family history of disorders.

5. To conduct research studies on drugs and patients.

6. To design and evaluate various research projects in health care.

7. To create awareness of communicable diseases or other disease conditions among society.

\section{Scope}

Firstly scope to any field is not depend on the course but it's depend on the individual, therefore we need to discover and need to mould to fit in that particular new scope. The myriad career options available to PharmD students:

1. Community Pharmacist

2. Pharmacovigilance

3. Medical writing

4. Clinical Research

5. NGO's

6. Conferences

\section{Discussion}

\section{Role of PharmD}

Doctor of pharmacy professionals are well trained in medication usage, dose adjustment and are involved in promotion of appropriate medication usage. In India as the entire prescribing pattern is under the control of physicians who are less familiar with pharmacology of drugs when compared with PharmD Nobody is superior, nobody is inferior in the field of healthcare everyone is with ultimate unique identity. It is the duty of Indian government to utilise the Doctor of Pharmacy in the actual patient care in Indian hospitals such as primary health care sectors where they can prove themselves.

The main role of PharmD doctors is to be conduct the patient counseling to educate the patient about the disease, drugs prescribed by doctors and also about diet of patient. Clinical pharmacist play a key role in improving patients health by Managing drug - drug interactions, drug interventions, dose adjustment etc.In pharmacovigilance this 
field can utilise the knowledge and skills of PharmD doctors. DIC (Drug information Centre) is the most outstanding area where PharmD doctors can effectively works.

There is great role of PharmD in society to provide care services meeting the therapeutic objectives of patient.

"It's not all about the PharmD the need for Indians it's about the more effective way to treat patient and providing everything about drugs to all for competent healthcare system of India"

\section{Conflict of Interest}

None.

\section{References}

1. American College of Clinical Pharmacy. The Definition of Clinical Pharmacy. Pharmacother. 2008; 28(6):816-7.
2. Kumar SBP, Dhalal P, Venkataraman R. Assessment of Clinical Pharmacist Intervention in Tertiary Care Teaching Hospital of southern India. Asian J Pharm Clin Res. 2013;25861

3. http://www.pci.nic.in/PDF-Files/PharmD-Revised-A.pdf

4. http://pharmawiki.in/scope-PharmD-india/

5. https://targetstudy.com/courses/PharmD.html

6. https://www.revolvy.com/main/index.php?s=Doctor $\% 20$ of $\% 2$ OPharmacy\&item_type=topic

7. https://scholar.google.co.in/scholar?hl=en\&as_sdt=0\%2C5\&q $=$ Medications++errors+in+India+statistics\&oq=\#d=gs_qabs\&u $=\% 23 \mathrm{p} \% 3 \mathrm{D} 0 \mathrm{ClP}-\mathrm{BjK} \mathrm{KLg}$

How to cite this article: Mundhe SA. PharmD: The need for Indians. Indian $J$ Pharm Pharmacol 2020;7(1):52-3. 